\title{
Synthesis of 5,6-Diphenyl-2,3-dihydro-1,2,4-triazine-3-thione as a New Reagent for Spectrophotometric Determination of Palladium
}

\author{
MALIHEH BARAZANDEH TEHRANI*, MARYAM TAHMASEBI, \\ EFFAT SOURI and HASHEM SHAMSA
}

Department of Medicinal Chemistry, Faculty of Pharmacy and Pharmaceutical Sciences Research Center, Tehran University of Medical Sciences, Tehran, Iran

barazand@sina.tums.ac.ir

Received 3 May 2014 / Accepted 16 May 2014

\begin{abstract}
A new chromogenic reagent for the sensitive and selective determination of $\mathrm{Pd}^{2+}$ ions in aqueous solution was synthesized. The reagent, 5,6-diphenyl-2,3-dihydro-1,2,4-triazine-3-thione, forms colored complexes with a few heavy metal ions. A 1:1 (M:L) yellowish orange colored complex of DPhDTT-Pd was formed in methanol. The molar absorptivity is $6.67 \times 10^{3} \mathrm{~L} \mathrm{~mol}^{-1} \mathrm{~cm}^{-1}$. Bee's law was obeyed in the concentration range of $10-50 \mu \mathrm{g} / \mathrm{mL}$ at $\lambda_{\max } 385 \mathrm{~nm}$. The accuracy and precision of the method were evaluated on within-day and between-day basis; the relative error was $\leq 3.13$ and the relative standard deviation was $\leq 3.96$. The method was successfully applied to the synthetic samples and results compared with atomic absorption method. There was no significant difference between two methods ( $\mathrm{p}>0.05)$.
\end{abstract}

Keywords: Palladium, Spectrophotometry, 5,6-Diphenyl-2,3-dihydro-1,2,4-triazine-3-thione

\section{Introduction}

Palladium is a critical metal regarding to its biological effects and mobility in the environment. World demand for palladium has been increased more than doubled in the past ten years ${ }^{1}$. The increasing demand for palladium in many (different) fields of technology led in the recent years to wide investigations on its toxicological effects ${ }^{2-6}$.

Several applications for palladium have been considered which its demand as automotive emission control catalyst (for auto catalyst industry) is by far the highest one. Further uses are in electrical equipment, dental appliances, jewellery and as catalyst for a wide variety of hydrogenation, oxidation, dehydration, and cyclization ${ }^{1,2,7-10}$.

Thus due to the urgent need for specific monitoring of Pd ion in many industrial, environmental, and food samples there have been a number of reports on Flame Atomic Absorption Spectroscopy (FAAS) ${ }^{11,12}$, (ETAAS) $)^{13}$, Inductively Coupled Plasma Mass Spectrometry ${ }^{10,14}$ and $\mathrm{x}$-ray fluorescence spectrometry ${ }^{15}$ in the literature. 
However the above mentioned techniques involve relatively high operational costs of instruments and /or materials and high purity solvents. Also some spectrophotometric methods have been reported for determination of $\mathrm{Pd}^{16-18}$. In recent years, we have prepared a number of triazine thione derivative reagents based on the 1,2,4-triazine-3-thion chromophore for determination ${ }^{19-22}$ of trace $\mathrm{Cu}^{2+}$, $\mathrm{Ni}$ and $\mathrm{Hg}$ ions.

\section{Experimental}

A shimadzu (160A, Kyoto, Japan) spectrophotometer with $1 \mathrm{~cm}$ quartz cells was used for all absorbance measurements under the following operating conditions. Scan speed high, Scan range 200-800 $\mathrm{nm}$ and slit width $2 \mathrm{~nm}$. A pH-meter model Metrohm (Switzerland) was used for the $\mathrm{pH}$ adjustments. Atomic absorption spectrophotometer (AA Vaian 220) was used in this study. NMR Spectra were recorded on a Bruker FT-500 Spectrometer (Bruker, Rheinstetten, Germany) with tetramethyl silan (TMS) as internal standard. Infrared spectra were obtained using a perkin-Elmer Model 781 spectrograph.

\section{Reagents}

Sodium hydroxide, palladium chloride, amyl nitrite, thiosemicarbazide and surfactants (tween 80, SDS) were purchased from Merck (Germany). All solvents used were of analytical grade prepared from Duksan (Korea). Britton-Robinson buffer was used in the $\mathrm{pH}$ range of 5-12. $\mathrm{NaOH}$ was used for $\mathrm{pH} 13$ and 14.

\section{Standard solutions}

A standard $\mathrm{Pd}^{2+}$ solution as chloride salt was prepared in a $100 \mathrm{~mL}$ volumetric flask. The stock solution $(100 \mu \mathrm{g} / \mathrm{mL})$ was used to prepare the working solutions by suitable dilutions with distilled water. The solutions were stable at least 30 days in room temperature. The reagent solution $(0.002 \mathrm{M})$ was prepared by dissolving accurately weight of pure reagent in sodium hydroxide $(1 \mathrm{M})$. Freshly prepared solutions were used for all experiments.

\section{General procedure}

In a $10 \mathrm{~mL}$ volumetric flask, $1 \mathrm{~mL}$ of the solution containing 5-50 $\mu \mathrm{g} \mathrm{Pd}^{2+}$ and $1 \mathrm{~mL}$ of a $0.002 \mathrm{M} \mathrm{DPhDTT}$ reagent was added and the solutions were diluted up to the mark with distilled water. Absorbance was measured at $385 \mathrm{~nm}$ against the reagent blank. Calibration graphs were constructed by plotting the absorbance $v s$. $\mathrm{Pd}^{2+}$ concentration.

\section{Synthesis of 5,6-diphenyl-2,3-dihydro-1,2,4-triazine-3-thion}

Synthesis of 5,6-diphenyl-2,3-dihydro-1,2,4-triazine-3-thion was performed according to the Scheme 1.

\section{Synthesis of 2-hydroxy-1,2- diphenyl ethanone}

In a $250 \mathrm{~mL}$ round bottom flask benzaldehyde $(4.7 \mathrm{~mol})$ and sodium cyanide $(1 \mathrm{~mol})$ were added to hot water /alcohol (1:1) solution and refluxed using water condenser for $4 \mathrm{~h}$. The product, 2-hydroxy-1,2-diphenyl ethanone, was collected by filtration and washed with cold water.

$\mathrm{mp}=127-129{ }^{\circ} \mathrm{C}$, yield $=75 \%$, IR $(\mathrm{KBr}) ; 3300 \mathrm{~cm}^{-1}, 1710 \mathrm{~cm}^{-1}, \mathrm{H}$ NMR: (CDCL3); 7.807.98(m, 2H), 7.50-7.70 (m, 3H), 7.30-7.40 (m, 5H), 0.01 (s, H)

\section{Synthesis of 5,6-diphenyl-2,3-dihydro-1,2,4-triazine-3-thion}

The product [1] was oxidized using $\mathrm{CuSO}_{4}$ in pyridine/water (2:1) solution in water bath (Temp. $80^{\circ} \mathrm{C}$ ) for $4 \mathrm{~h}$. The white colored powder, 1,2-diphenyl ethane-1,2-dione, was separated, 
washed with hydrochloric acid and used for synthesis of the reagent. The product was added to thiosemicarbazide and potassium carbonate in ethanolic media and refluxed at $80{ }^{\circ} \mathrm{C}$ for $5 \mathrm{~h}$.

On cooling the reaction mixture a yellow colored product was separated out and crystallized using water /alcohol, yield $80 \%, \mathrm{mp}=125-130{ }^{\circ} \mathrm{C}$.

IR(KBr) 3410 ,3338.6, 3253, 1602.6, 1482.3, 1445.5, H NMR 7.34-7.81(m, 10 H Ar)

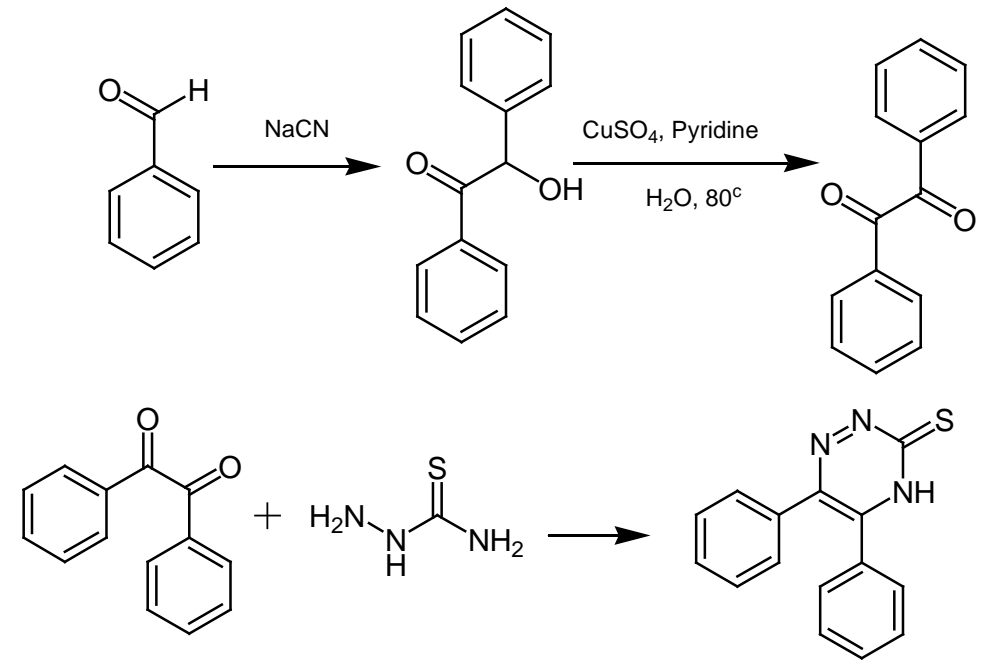

Scheme 1. Synthesis of 5,6-diphenyl-2,3-dihydro-1,2,4-triazine-3-thion

\section{Composition of the absorbent complex}

Adjusting the $\mathrm{pH}$ values of the working solution was carried out using Britton-Rabinson buffer solution ( $\mathrm{pH}=3-12)$. The effect of surfactants was evaluated using different amounts of sodium lauryl sulfate $(0.1 \%)$, cetyltrimethyl ammonium chloride $(0.1 \%)$ and tween 80 (3\%). The composition of Pd-DPhDTT was examined by job's method. Continuous variation and limiting logarithmic method were used to determine the stoichiometry of ligand to metal ion. The proper ratio of ligand/metal for complex formation was determined by mol ratio method.

\section{Results and Discussion}

\section{Selection of the reaction solvent}

5,6-Diphenyl-2,3-dihydro-1,2,4-triazine-3-thione (DPhDTT) was synthesized due to our resent studies for preparing more sensitive and selective reagent for determination of trace amount of some toxic and nutritional ions. DPhDTT forms stable and yellow orange colored complex with $\mathrm{Pd}(\mathrm{II})$ in some aqueous and non-aqueous solvents. A solvent which could dissolve both the DPhDTT reagent and the DPhDTT-Pd complex would be a suitable solvent. On the other hand acceptable absorbance spectra for the formed complexes should be observed without the interference from the reagent. In this study, ethyl alcohol, methyl alcohol, water (basic media), chloroform, hexane, dichloromethane and acetonitrile were used. As seen from Table 1 the best results were observed by using methanol as a proper solvent. In this condition the DPhDTT-Pd showed a maximum absorption wavelength at 385 $\mathrm{nm}$ which was used for spectrophotometric measurements (Figure 1). No interference was observed from the reagent at this wavelength. 
Table 1. Effect of the solvent system on the absorbance value of Pd(II)-DPhDTT complex $(20 \mu \mathrm{g}$ Pd (II)/mL)

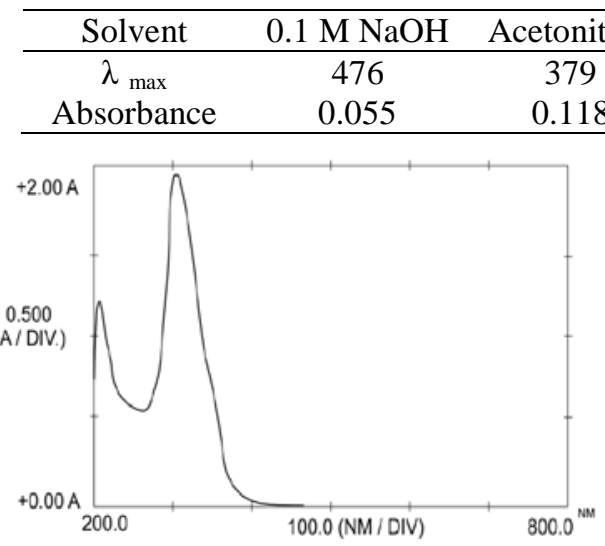

(a)

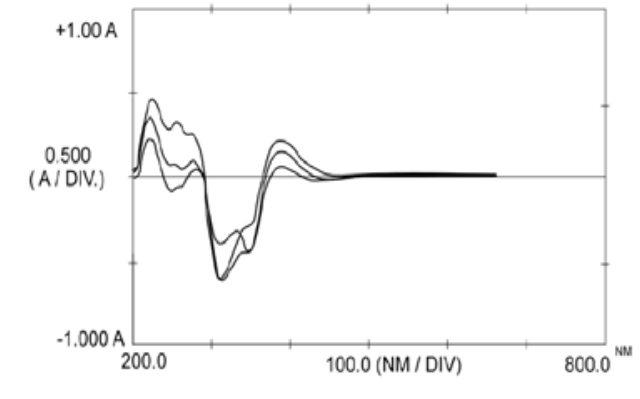

(b)

Figure 1. UV-VIS absorption spectra of a) DPhDTT, b) Pd-DPhDTT complex against reagent blank in three 10,15 and $20 \mu \mathrm{g} / \mathrm{mL}\left(\lambda_{\max }=385 \mathrm{~nm}\right)$

\section{Effect of $\mathrm{pH}$ and surfactants on complex formation}

The effect of $\mathrm{pH}$ on the complex formation was studied using Britton-Robinson buffer ( $\mathrm{pH}=$ 3-11), sodium hydroxide $1 \mathrm{M}$, water and methanol. The results showed in Figure 2 reveal that the absorbance of the complex decreased in the presence of buffer and the maximum absorbance was obtained in methanol. Thus, methanolic solvent with no buffer was used for the subsequent work. The effect of cationic, anionic and non-ionic surfactants was studied using different amounts of cetrimide, sodium lauryl sulfate and tween 80 . The results showed that surfactants caused turbidity in complex solution.

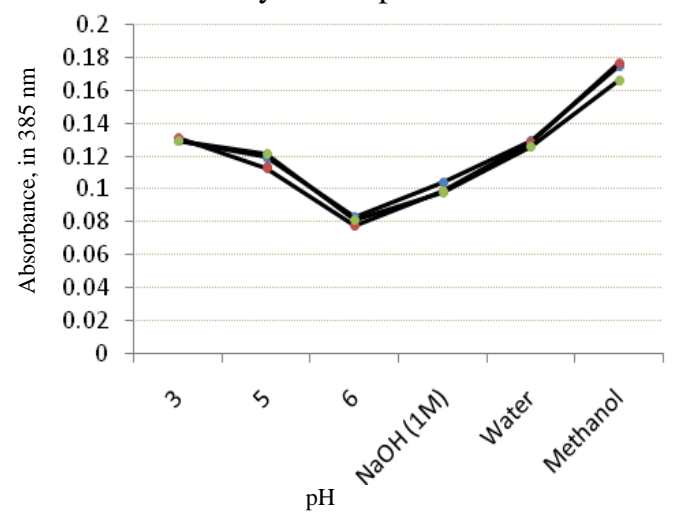

Figure 2. Influence of $\mathrm{pH}$ on the absorbance of Pd-DPhDTT complex

\section{Stoichiometry of the complex}

Three different methods, mole ratio, continuous variation and limiting logarithmic method were used to find out the stoichiometry of the reaction. According to the results shown in Figures 3-5, it was concluded that a complex with a 1:1 molar ratio was formed between the reagent and Pd. 


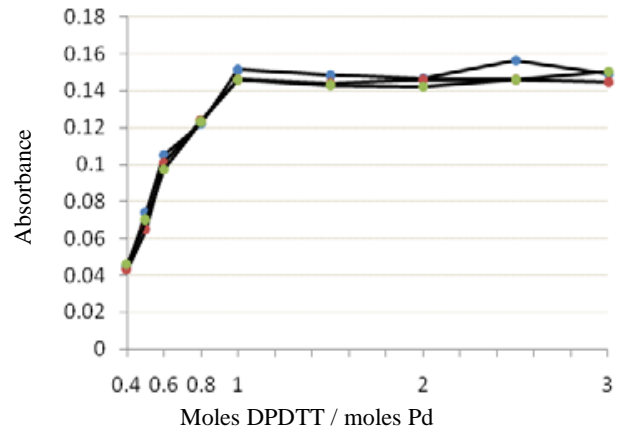

Figure 3. Variation of the absorbance by mole ratio method

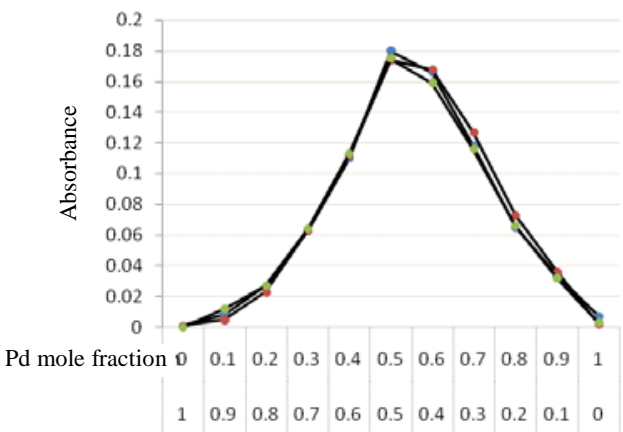

Figure 4. Composition of Pd-DPhDTT complex by continuous variation method

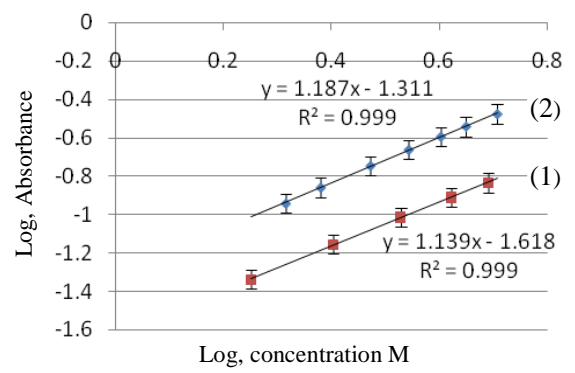

Figure 5. Limiting Logarithmic plot for ratio of $\mathrm{Pd}(\mathrm{II})$ and reagent (DPhDTT), log abs versus log [DPhDTT] (1), log abs versus log [Pd](2)

Stability of the complex

The formed DPhDTT-Pd complex was stable at least for $4 \mathrm{~h}$ (recovery>98\%).

\section{Linearity}

Six series of standard calibration solutions of Pd(II) were prepared in the range of 10-50 $\mu \mathrm{g} / \mathrm{mL}$ and treated according to the general procedure. The results are shown in Table 2.

\section{Accuracy and Precision}

To find out the accuracy and precision of the method three series of standard solutions of $\operatorname{Pd}(\mathrm{II})$ at $10,20,30,40$ and $50 \mu \mathrm{g} / \mathrm{mL}$ were used. The within-day and between-day accuracy and precision are presented in Table 3. Acceptable CV and error values showed the suitability of the method for the determination of Pd samples in the studied calibration range.

Table 2. Analytical parameters of calibration curves of Pd(II)-DPhDTT. (n=9)

\begin{tabular}{ll}
\hline \multicolumn{1}{c}{ Parameters } & \\
\hline Linearity & $10.00-50.00 \mu \mathrm{g} / \mathrm{mL}$ \\
Limit of detection & $2.03 \mu \mathrm{g} / \mathrm{mL}$ \\
Limit of quantification & $6.15 \mu \mathrm{g} / \mathrm{mL}$ \\
Molar absorptivity & $6.67 \times 10^{3}$ \\
Regression equation & $\mathrm{Y}=0.07266 \mathrm{x}-0.0353$ \\
SD of slope & $2.43 \times 10^{-4}$ \\
RSD of slope & 0.34 \\
SD of intercept & $6.4 \times 10^{-3}$ \\
Coefficient correlation & 0.9968 \\
\hline
\end{tabular}


Table 3. Accuracy and precision data for determination of palladium in one day $(n=3)$ and four subsequent days $(\mathrm{n}=12)$

\begin{tabular}{cccc}
\hline Added, $\mu \mathrm{g} / \mathrm{mL}$ & Found, $\mu \mathrm{g} / \mathrm{mL}$ & $\mathrm{CV} \%$ & Error\% \\
\hline Within-day $(\mathrm{n}=3)$ & & & \\
10.00 & $10.30 \pm 0.27$ & 2.67 & 3.13 \\
20.00 & $20.25 \pm 0.39$ & 1.91 & 1.27 \\
30.00 & $29.69 \pm 0.26$ & 0.89 & -1.03 \\
40.00 & $40.59 \pm 0.56$ & 1.39 & 1.47 \\
50.00 & $50.77 \pm 0.10$ & 0.20 & 1.53 \\
\hline Between-day (n=12) & & & \\
10.00 & $10.16 \pm 0.40$ & 3.96 & 1.58 \\
20.00 & $20.18 \pm 0.52$ & 2.59 & 0.92 \\
30.00 & $29.68 \pm 0.52$ & 1.75 & -1.08 \\
40.00 & $39.93 \pm 0.62$ & 1.55 & -0.19 \\
50.00 & $50.82 \pm 0.36$ & 0.71 & 1.64 \\
\hline
\end{tabular}

\section{Sensitivity}

The limit of quantification (LOQ), limit of detection (LOD) and molar absorptivity of the proposed method, calculated according to the following equations, were 6.15 and $2.03 \mu \mathrm{g} / \mathrm{mL}$ and $6.67 \times 10^{3}$ respectively (Table 2 ). $\mathrm{LOD}=3.3 \mathrm{~S} / \mathrm{b}, \mathrm{LOQ}=10 \mathrm{~S} / \mathrm{b}$, (where $\mathrm{S}$ is the standard deviation of the ordinate intercept and $\mathrm{b}$ is the slope of the regression line.)

\section{Application of the method}

Three synthetic sample solutions containing 25, 30 and $45 \mu \mathrm{g}$ Pd was used as the real sample. The solutions were prepared and treated according to the general procedure. The Pd amount was also determined by a reference method. The results are presented in Table 4 which shows no interference with the media.

Table 4. Application of the proposed method to the determination of $\mathrm{Pd}(\mathrm{II})$ in synthetic sample $(\mathrm{n}=4)$

\begin{tabular}{ccccccc}
\hline \multirow{2}{*}{ Sample } & Added & \multicolumn{2}{c}{ Found (mean $\pm \mathrm{sd}$ ) } & & \\
\cline { 3 - 4 } & & $\begin{array}{c}\text { Proposed } \\
\text { method }\end{array}$ & $\begin{array}{c}\text { A. A. } \\
\text { method }\end{array}$ & Statistical Tests & & \%Recovery \\
\hline 1 & 25.00 & $24.50 \pm 0.010$ & $24.90 \pm 0.02$ & $\mathrm{~T}=0.265$ & $\mathrm{~F}=0.647$ & $98.30 \pm 0.43$ \\
2 & 30.00 & $30.51 \pm 0.061$ & $30.11 \pm 0.05$ & $\mathrm{~T}=0.360$ & $\mathrm{~F}=0.741$ & $101.90 \pm 2.03$ \\
3 & 45.00 & $44.75 \pm 0.039$ & $44.85 \pm 0.07$ & $\mathrm{~T}=0.284$ & $\mathrm{~F}=0.832$ & $99.30 \pm 0.88$ \\
\hline
\end{tabular}

*Theoretical values of $t$ and $F$ at $p=0.05$ and $95 \%$ confidence are 2.776 and 6.388 respectively.

\section{Conclusion}

From the results of this study it can be concluded that the proposed spectrophotometric method using the new sensitive and selective reagent DPhDTT for determination of Pd is a simple and reliable and inexpensive method. However in comparison with the results obtained with atomic absorption method, the proposed method can be recommended in routine analysis

\section{Acknowledgment}

This study was part of an M.D. thesis/dissertation supported by Tehran University of Medical Sciences and Pharmaceutical Sciences Research Center. 


\section{References}

1. http://www.napalladium.com/palladium/supply-and-demand/default.aspx

2. Peter Albers, Jorg Pietsch and Stewart F Parker, J Mole Catal A: Chem., 2001, 173(1-2), 275-286; DOI:10.1016/S1381-1169(01)00154-6

3. WHO, International program on chemical safety (IPCS) Environmental Health Criteria (EHC) 226. Palladium, Geneva: World Health Organization, 2002, 202.

4. Sures B, Singer C and Zimmermann S, In: Zereini F and Alt F, (Eds.), Palladium emissions in the environment: Analytical methods, environmental assessment and health effects. Springer, Heidelberg, 2006, 489-499.

5. Vamnes J S, Lygre J B, Gronningsaeter A G and Gjerdet N R, Community Dentistry and Oral Epidemiology, 2004, 32(2), 150-157; DOI:10.1111/j.0301-5661.2004.00148.x

6. Iavicoli I, Fontana L and Bergamaschi A, Encyclopedia of Environmental Health, 2011, 307-314; DOI:10.1016/B978-0-444-52272-6.00575-4

7. Janet Kielhorn, Christine Melber, Detlef Keller and Inge Mangelsdorf, Int J Hygiene Environ Health, 2002, 205(6), 417-432; DOI:10.1078/1438-4639-00180

8. Georges Audi, Bersillon O, Blachot J and Wapstra A H, Nuclear Physics A(Atomic Mass Data Center), 2003, 729, 3-128.

9. Rushforth R. Platinum Metals Review. 2004, 48(1), 30-31.

10. Leopold K, Maier M, Weber S and Schuster M, Environ Pollution, 2008, 156(2), 341-347; DOI:10.1016/j.envpol.2008.02.005

11. Bahar S and Hosseini H, J Iranian Chem Soc., 2014, 11(2), 579-586.

12. Afzali D, Mostafavi A and Afzali Z, J AOAC Int., 2010, 93(6), 1952-6.

13. Hann S, Rudolph E, Kollensperger G and Reiter C, In Zereini F and Alt F, (Eds.), Palladium Emission in the Environment Assessment and Health Effects. Springer, Heidelberg, 2006, 73-82.

14. Rauch S, Morrison G M and, Moldovan M, Sci Total Environ., 2002, 286(1-3), 243251; DOI:10.1016/S0048-9697(01)00988-3

15. Messerschmidt J, Von Bohlen A, Alt F and Klockenkamper R, Analyst, 2000, 125, 397-399; DOI:10.1039/B000471P

16. Varinder Kaur, Ashok Kumar Malik and Neelam Verma. Turk J Chem., 2010, 34, 295-306.

17. Vesnavasi, Jasminasavi and Nikolavukeli, J Serb Chem Soc., 2004, 69(4), 309-317; DOI:10.2298/JSC0404309V

18. Walla Mohammed and Hussain Jasem Mohammed, Int J Civil Environ Engg IJCEEIJENS, 2013, 13(6), 37-40.

19. Shamsa F and Barazandeh Tehrani M, Daru, 2004, 12(2), 76-80.

20. Maliheh Barazandeh Tehrani, Hutan Ghanbari, Effat Souri, Fazel Shamsa and Mohsen Amini, Int J Anal Chem., 2014, Article ID 260179, 6 pages; DOI:10.1155/2014/260179

21. Maliheh Barazandeh Tehrani, Mohammad Sadegh Mirkamali S and Effat Souri, Asian J Chem., 2012, 24(10), 4517-4521.

22. Maliheh Barazandeh Tehrani, Alireza Forumadi, Hashem Shamsa S and Ehsan Mojtahedi. Res J Pharm Biol Chem Sci., 2012, 3(4), 65-72. 